\title{
Use of Na-modified clinoptilolite for the removal of terbium ions from aqueous solution
}

\author{
O. VYVIURSKA ${ }^{1}$, V. VASYLECHKO ${ }^{1,2 *}$, G. GRYSHCHOUK ${ }^{1}$, Ya. KALYCHAK $^{1}$, V. ZAKORDONSKIY ${ }^{1}$ \\ ${ }^{1}$ Ivan Franko National University of Lviv, \\ Kyryla i Mefodiya St. 6, 79005 Lviv, Ukraine \\ ${ }^{2}$ Lviv Academy of Commerce, Samchouk St. 9, Lviv 79005, Ukraine \\ * Corresponding author: vasylechko@ukr.net
}

Received September 29, 2012; accepted December 26, 2012; available on-line July 5, 2013

In this study, Na-modified Transcarpathian clinoptilolite was used for preconcentration of trace amounts of terbium(III) ions from aqueous solutions. The sorbent was characterized by thermogravimetric analysis. The influence of the preliminary thermal treatment on the sorption activity of Na-modified clinoptilolite was thoroughly investigated. In addition, it was found that such characteristics of the solution as the terbium concentration, acidity, and ion strength have an effect on the sorption capacity of the zeolite in dynamic conditions. The optimum $\mathrm{pH}$ range of the solution was found to be 8.8-9.0. A preliminary thermal treatment of Na-clinoptilolite in the temperature range $475-700^{\circ} \mathrm{C}$ increased the sorption capacity of the sorbent. $7 \mathrm{M}$ nitric acid, 6M hydrochloric acid, and $1 \mathrm{M} \mathrm{NaCl}$ solutions were identified as effective desorbents of terbium(III) ions from Na-clinoptilolite. Furthermore, the influence of the most common ions on the uptake capacity of the sorbent was evaluated.

Terbium / Na-clinoptilolite / Sorption / Solid-phase extraction

\section{Introduction}

Recently, many research studies have been devoted to the investigation of physical properties of terbium. The results allow extending the applications of lanthanide ions as phosphors [1-3], and as doping components in electrochemical devices [4,5] and different other materials [6-8]. Moreover, the luminescence properties of terbium are widely used for highly sensitive determinations of both organic [9-11] and inorganic [12,13] compounds. Consequently, it is an important issue to find effective and selective sorbents for the preconcentration of terbium ions. For this purpose, resins and modified forms of these [14-16], activated carbon [17], and crown ether adsorbents [18] have mostly been applied.

At the same time, natural zeolites are broadly used for removal of ammonium, heavy metals and organic contaminations from water and wastewater [19-21]. Clinoptilolite is one of the most widespread and popular natural zeolites, which can be found in different parts of the world. Besides its accessibility, this sorbent is environmentally safe, and possesses such important characteristics as the possibility to concentrate trace amounts of compounds, large sorption capacity, resistance to aggressive media and high temperatures, regeneration ability, the sieve effect and selective cation-exchange properties. It should be noted that clinoptilolite can be modified by organic and inorganic compounds. One of the most used forms of clinoptilolite is its Na-modified form with enhanced sorption properties in comparison with its natural form [22-24].

According to $[25,26], \quad$ Transcarpathian clinoptilolite effectively sorbs terbium(III) ions from aqueous solutions. Consequently, Tb-clinoptilolite composite materials could be used for the determination of nanogram amounts of terbium(III) ions in the presence of other lanthanides [26]. The sorption properties of the acid form of Transcarpathian clinoptilolite towards terbium(III) ions have been investigated thoroughly [27]. However, little is known about its Na-form applied for this purpose.

In order to study the possibility to utilize this natural alumosilicate as a solid phase extraction sorbent, an investigation of the sorption properties of Na-modified Transcarpathian clinoptilolite towards trace amounts of terbium(III) ions in aqueous solution was carried on, and the results are presented in this paper. 


\section{Experimental}

Natural clinoptilolite was collected from a deposit near the village Sokyrnytsia in the Ukrainian Transcarpathian region. The content of the main component is $85-90 \%$ for this sorbent. A previous analysis showed that the specific surface area of Transcarpathian clinoptilolite is $59.0 \mathrm{~m}^{2} / \mathrm{g}$ [28]. The chemical composition of the sorbent was as follows [29] (wt.\%), $\mathrm{SiO}_{2}: 67.29 ; \mathrm{Al}_{2} \mathrm{O}_{3}: 12.32 ; \mathrm{TiO}_{2}: 0.26$; $\mathrm{Fe}_{2} \mathrm{O}_{3}$ : 1.26; FeO: 0.25; $\mathrm{MgO}: 0.99$; $\mathrm{CaO}: 3.01 ; \mathrm{Na}_{2} \mathrm{O}$ : 0.66; $\mathrm{K}_{2} \mathrm{O}: 2.76 ; \mathrm{H}_{2} \mathrm{O}: 10.90$. The clinoptilolite sample was ground and sieved to $0.21-0.31 \mathrm{~mm}$, washed with distilled water and dried at room temperature.

The Na-form of Transcarpathian clinoptilolite was obtained according to [30]. The powder of clinoptilolite was preconditioned with a $0.25 \mathrm{M} \mathrm{HCl}$ solution for $4 \mathrm{~h}$ at room temperature. Then the zeolite fraction was separated, washed with distilled water and treated with an $1 \mathrm{M} \mathrm{NaCl}$ solution for 1-1.5 h (repeated seven to eight times). The obtained $\mathrm{Na}$-clinoptilolite was dried at room temperature.

All of the reagents were analytical grade. A standard solution of terbium(III) was prepared by dissolving metallic terbium (purity 99.9\%) in nitric acid (1:1). The reagent solutions were made in bidistilled water, except for a $0.05 \%$ solution of sulpharsazene, which was prepared with a $0.05 \mathrm{M}$ borax solution as solvent.

The sorption properties of Na-clinoptilolite were investigated under dynamic and static conditions. The terbium(III) solution was passed through a sorption cartridge filled with sorbent at a flow rate of $5 \mathrm{~mL} / \mathrm{min}$, using a peristaltic pump under dynamic conditions. This procedure of the evaluation under dynamic conditions is described more in detailed in [31].

The desorption process of $\mathrm{Tb}(\mathrm{III})$ ions was studied under static conditions. $0.6 \mathrm{~g}$ of Na-clinoptilolite powder was added to $50 \mathrm{~mL}$ of a terbium solution with a concentration of $2 \mu \mathrm{g} / \mathrm{mL}$ at $p H 8.8$ and left for $24 \mathrm{~h}$. After filtration the sorbent was diligently washed with bidistilled water and then $10 \mathrm{~mL}$ of desorbent solution was added. Desorption of terbium ions from the zeolite was performed in two ways. Firstly, the desorption solution was boiled with Na-clinoptilolite containing terbium(III) ions for $10 \mathrm{~min}$ in a sand bath. Secondly, the same reagent mixture was shaken for $60 \mathrm{~min}$ at room temperature. The mixture was filtered, the filtrate was extracted, transferred to a volumetric flask and diluted to $25 \mathrm{~mL}$ with bidistilled water.

The terbium content in the solutions was determined spectrophotometrically with arsenazo III according to the following technique: $2 \mathrm{~mL}$ of a $1 \%$ ascorbic acid solution was added to the solution of terbium ( $p H 1.0$ ). After $2 \mathrm{~min} 1 \mathrm{~mL}$ of $10 \%$ sodium potassium tartrate, $1 \mathrm{~mL}$ of formic buffer $(p H 3.5)$ and $2 \mathrm{~mL}$ of $0.05 \%$ arsenazo III were added. The volume of the solution was adjusted to $20 \mathrm{~mL}$ with distilled water and the $p H$ was fixed at 2.6 with a $\mathrm{NaOH}$ solution $(\sim 0.1 \mathrm{~N})$. The solution was transferred to a volumetric flask and its volume was adjusted to $25 \mathrm{~mL}$. Then the solution absorbance was measured at $650 \mathrm{~nm}$ by using a DR/4000 V Spectrophotometer (HACH). A "blank" sample containing all the components except terbium(III) ions was used as reference.

Thermogravimetric analysis was carried out by the derivatographic method, employing a Paulik-Paulik Erdey Q-1500D (MOM, Hungary) system at temperatures up to $1000^{\circ} \mathrm{C}$, with $10^{\circ} \mathrm{C} / \mathrm{min}$ heating rate. The evaluations were performed using corundum crucibles in air. $\mathrm{Al}_{2} \mathrm{O}_{3}$ was used as a standard.

A muffle oven (SNOL 7,2/1100, Lithuania) and a drying stove (WSU 200, Germany) were used during the investigations.

\section{Results}

\subsection{Influence of the acidity}

In order to optimize the conditions for $\mathrm{Tb}(\mathrm{III})$ ion sorption on the Na-form of clinoptilolite, the influence of the acidity of the solution from which preconcentration of the analyte was carried out was studied (Fig. 1). As demonstrated by the graph, the maximum adsorption capacity of the Na-form of the zeolite towards terbium(III) is observed in a slightly alkaline medium ( $p H$ 8.8). However, neutral and slightly acid solutions of terbium(III) could be accepted for studying preconcentration.

\subsection{Influence of the terbium(III) concentration}

Since it is known that Transcarpathian clinoptilolite has the ability to selectively uptake trace amounts of compounds, the influence of the concentration of terbium(III) ions in the solution on the sorption properties of $\mathrm{Na}$-clinoptilolite towards the investigated lanthanide ions was studied.

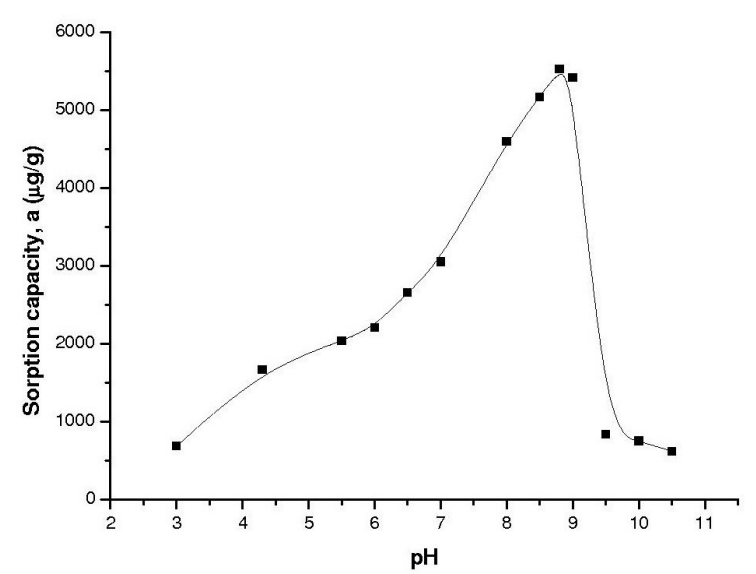

Fig. 1 Dependence of the sorption capacity, $a$, of Na-clinoptilolite towards terbium(III) on the $p H$ value of the aqueous solution. 
As can be seen from Table 1, the sorption properties of the zeolite towards terbium(III) ions decrease with increasing concentration. This result may be attributed to the partial formation of terbium polynuclear complexes at higher concentrations. A similar conclusion was presented by the authors of [32]. In their opinion, at higher concentrations in aqueous solutions lanthanum ions can exist as polynuclear complexes $\mathrm{La}_{2}(\mathrm{OH})_{2}{ }^{4+}, \mathrm{La}_{3}(\mathrm{OH})_{5}{ }^{4+}$, and $\mathrm{La}_{5}(\mathrm{OH})_{9}{ }^{6+}$.

\subsection{Influence of the thermal treatment}

To characterize the sorbent, thermogravimetric analyses of Na-clinoptilolite (Figs. 2,3) were performed.

As demonstrated by the graphs (Figs. 2,3), the TGand DTG-thermograms of natural and Na-modified clinoptilolite are almost identical. A much wider temperature interval with a maximum velocity of water loss (the range of DTG maxima) could be observed for the $\mathrm{Na}$-sample with a greater mass loss in this temperature range, compared to the natural zeolite, $5.0 \%$ and $2.6 \%$ respectively. These results may suggest that Na-clinoptilolite possesses a more developed effective surface with molecular water physically and chemically sorbed on it. At the same time, the DTG curve of the modified zeolite possesses an extended isokinetic range (at $470-510^{\circ} \mathrm{C}$ ), and

Table 1 Dependence of the sorption capacity of the uncalcined $\mathrm{Na}$-form of clinoptilolite on the $\mathrm{Tb}(\mathrm{III})$ concentration ( $p H 8.8)$.

\begin{tabular}{c|c}
\hline $\begin{array}{c}\text { Concentration of } \mathrm{Tb}(\mathrm{III}), \\
\mu \mathrm{g} / \mathrm{mL}\end{array}$ & $\begin{array}{c}\text { Sorption capacity, } \\
\mu \mathrm{g} / \mathrm{g}\end{array}$ \\
\hline 1.0 & 5521 \\
3.0 & 2200 \\
5.0 & 750 \\
\hline
\end{tabular}

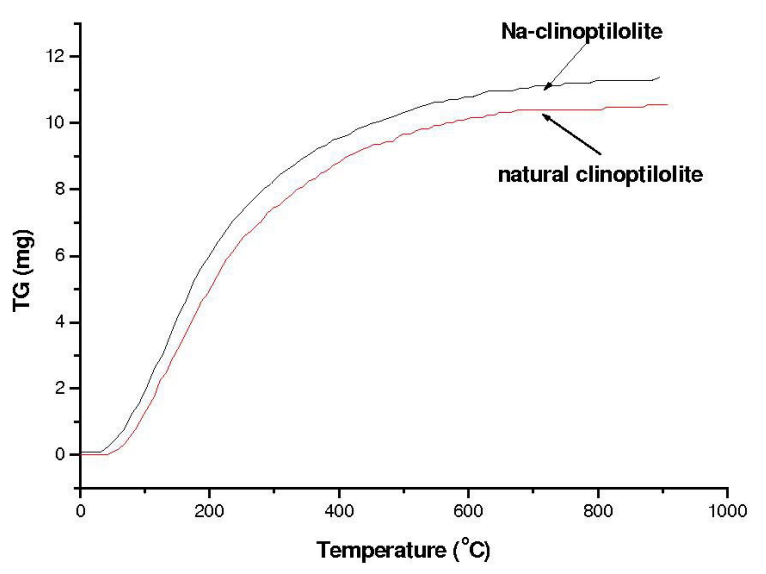

Fig. 2 TG thermograms of natural and Na-modified Transcarpathian clinoptilolite.

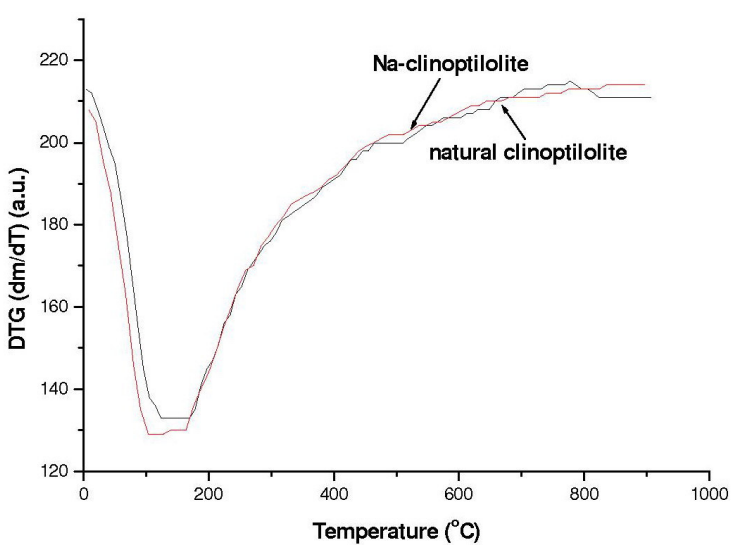

Fig. 3 DTG thermograms of natural and Na-modified Transcarpathian clinoptilolite.

this fact confirms the previous assumption. In these temperature intervals, a process of dehydroxylization of the sorbent with discharge of isolated $\mathrm{OH}$-groups takes place. The $0.5 \mathrm{mg}$ and $0.4 \mathrm{mg}$ decrease of the zeolite mass for $\mathrm{Na}$ - and natural clinoptilolite could be used as a criterion to estimate the effective adsorption surface.

In [33], the authors observed slightly different results, in particular the loss of water for Na-clinoptilolite calcined at $250^{\circ} \mathrm{C}$ was smaller than for the natural form treated at the same conditions. In addition, the investigations in [34] disclosed certain increase of the specific surface area of modified clinoptilolite from Western Anatolia, Turkey.

It is known that a preliminary thermal treatment may activate the sorption properties of zeolites $[27,28,35]$. In order to verify the influence of this parameter on the efficiency of sorption of terbium(III) ions on Na-clinoptilolite, an investigation was performed. As demonstrated by Fig. 4, the studied factor promotes a 1.7 times enhancement of the sorption properties in the temperature range $475-700^{\circ} \mathrm{C}$, as compared with uncalcined Na-clinoptilolite. At these conditions, processes of dehydroxylization of the internal surface of the sorbent and formation of siloxane bonds occur.

\subsection{Influence of the presence of admixtures}

A significant factor for creating a new analytical procedure is the influence of the salt concentration, which defines the ionic force. As can be seen from the obtained data (Table 2), the sorption properties of calcined Na-clinoptilolite towards lanthanide(III) ions, decrease with increasing concentration of sodium nitrate. Meanwhile, the sorption properties remain at a constant value when the salt concentration is further increased. The obtained results are important for the elaboration of a procedure of terbium(III) preconcentration by the zeolite. 
The influence of the presence of foreign ions commonly found in wastewater on the characteristics of the preconcentration method was studied. Permissible multiple content of admixtures without considerable effect on the maximum sorption properties of Na-clinoptilolite towards terbium(III) ions are presented in Table 3.

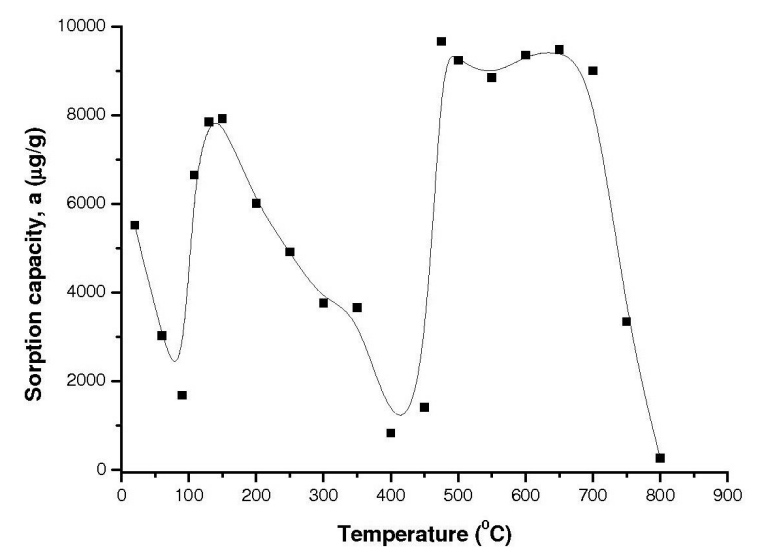

Fig. 4 Dependence of the sorption capacity of Na-modified clinoptilolite towards terbium(III) on thermal treatment applied in the range from 20 to $800^{\circ} \mathrm{C}$. The following conditions were used: time of heat treatment, $2.5 \mathrm{~h}$; $\mathrm{Tb}$ (III) ion concentration in the solution $=1.0 \mu \mathrm{g} / \mathrm{mL} ; p H$ 8.8 ; velocity of solution passing through the sorbent $5 \mathrm{~mL} / \mathrm{min}$.

Table 2 Influence of the salt concentration on the sorption capacity of Na-clinoptilolite, calcined at $480^{\circ} \mathrm{C}$, towards $\mathrm{Tb}(\mathrm{III})$ ions (concentration of $\mathrm{Tb}(\mathrm{III})-1 \mu \mathrm{g} / \mathrm{mL}, p H 8.8$ ).

\begin{tabular}{c|c}
\hline $\mathrm{C}\left(\mathrm{NaNO}_{3}\right), \mathrm{mol} / \mathrm{L}$ & Sorption capacity, $\mu \mathrm{g} / \mathrm{g}$ \\
\hline $1.0 \cdot 10^{-4}$ & 9000 \\
$1.0 \cdot 10^{-3}$ & 5333 \\
$1.0 \cdot 10^{-2}$ & 5300 \\
\hline
\end{tabular}

Table 3 Permissible multiple content of admixtures for sorption of $\mathrm{Tb}$ (III) ions from aqueous solutions of Na-modified clinoptilolite (concentration of $\mathrm{Tb}(\mathrm{III})-1 \mu \mathrm{g} / \mathrm{mL}, p H 8.8$ ).

\begin{tabular}{c|c}
\hline Admixture & Permissible multiple content \\
\hline $\mathrm{K}^{+}$ & 50 \\
$\mathrm{NH}_{4}^{+}$ & 100 \\
$\mathrm{Mg}^{2+}$ & 50 \\
$\mathrm{Ca}^{2+}$ & 100 \\
$\mathrm{Zn}^{2+}$ & 0.5 \\
$\mathrm{NO}_{3}^{-}$ & 100 \\
$\mathrm{Cl}^{-}$ & 100 \\
\hline
\end{tabular}

\subsection{Desorption of preconcentrated terbium(III) ions}

Since the maximum sorption capacity has not to be used for the analyte concentration, the values of permissible admixture contents could be larger. In order to find the effective desorbent of preconcentrated terbim(III) ions from the zeolite structure, both different compounds $\left(\mathrm{HCl}, \mathrm{HNO}_{3}\right.$, $\mathrm{H}_{2} \mathrm{SO}_{4}, \mathrm{NaCl}$ ) and conditions were utilized. As can be seen from the data (Table 4), 7M nitric acid, 6M hydrochloric acid and $1 \mathrm{M} \mathrm{NaCl}$ solutions $(p H 4.1)$ are very efficient for this purpose. Moreover, it was found that the thermal activation procedure is more useful for desorption, compared to the shaking technique.

\section{Discussion}

In our previous works $[28,35]$ it was shown that both the surface chemistry of Transcarpathian clinoptilolite and forms of terbium(III) ions in aqueous solution at different solution acidity, have an influence on the sorption process. At a low $p H$ value, the dissociation of surface hydroxyl groups on the modified clinoptilolite, responding to the adsorption of heavy metals, is practically suppressed and, as a result, the sorption activity of the sorbent relative to terbium(III) ions is low. Furthermore, a competitive reaction of ion exchange may take place at these conditions. An increase of the $p H$ of the solution promotes a dissociation process, and leads to an enhancement of the sorption properties of the clinoptilolite. The predominant forms of terbium(III) ions change from cation aqua complexes $\left[\mathrm{Tb}\left(\mathrm{H}_{2} \mathrm{O}\right)_{8}\right]^{3+}$ to cation hydroxy aqua $\left[\mathrm{Tb}(\mathrm{OH})_{2}\left(\mathrm{H}_{2} \mathrm{O}\right)_{6}\right]^{+}$and neutral aqua hydroxo complexes $\left[\mathrm{Tb}(\mathrm{OH})_{3}\left(\mathrm{H}_{2} \mathrm{O}\right)_{5}\right]$.

Obviously, terbium(III) cation and neutral aqua hydroxo complexes are better sorbed by Na-modified Transcarpathian clinoptilolite than other terbium(III) complexes. In the case of more basic solutions, the anionic complexes probably dominate, and do practically not concentrate on the zeolite. Investigations of the sorption processes on natural heulandite [36,37] and synthetic mordenite [38] show that terbium(III) ions generally sorb on zeolites in the form of hydrolyzed cation and neutral complex ions.

Table 4 Desorption of terbium(III) ions from Na-modified clinoptilolite.

\begin{tabular}{c|c}
\hline Desorbent & Desorption (\%) \\
\hline $7 \mathrm{M} \mathrm{HNO}_{3}$, (boiling) & $98-100$ \\
$7 \mathrm{M} \mathrm{HNO}_{3}$, (shaking) & 72 \\
$6 \mathrm{M} \mathrm{HCl}^{\text {(boiling) }}$ & $95-100$ \\
$3.6 \mathrm{M} \mathrm{H}_{2} \mathrm{SO}_{4}$ (shaking) & 30 \\
$1 \mathrm{M} \mathrm{NaCl}, p H 4.1$ (boiling) & 94 \\
\hline
\end{tabular}


The authors of [39] have demonstrated that $\mathrm{La}^{3+}$ and $\mathrm{Nd}^{3+}$ ions sorb better on biotite with a layer structure than on crystal heulandite, which is rather similar to clinoptilolite. The degradation of the crystal structure of Na-clinoptilolite and the formation of siloxane bonds in the tetrahedral vacancies, caused by the dealuminization stage of a partial amorphization process at high temperatures, probably promote the sorption of terbium(III) ions on the zeolite.

\section{Conclusions}

The results obtained in this work show that the most effective sorption of terbium(III) ions by the Na-form of Transcarpathian zeolite is observed for a slightly basic solution. In addition, this sorbent is selective to trace amounts of the lanthanide. A preliminary thermal treatment of modified clinoptilolite at $480-700^{\circ} \mathrm{C}$ improves the sorption capacity by a factor 1.7. Thermogravimetric investigations of the sorbent were carried out. Nitric and hydrochloric acids, and $1 \mathrm{M} \mathrm{NaCl}$ solutions ( $p H 4.0)$ are efficient desorbents of terbium(III) ions. As to the influence of the presence of foreign ions on the sorption selectivity, their permissible multiple contents have sufficiently large values. The results indicate possible application of the Na-form of Transcarpathian clinoptilolite for preconcentration of terbium(III) ions.

\section{Acknowledgements}

This work was partially funded by the Ministry of Education, Science, Youth and Sports of Ukraine.

\section{References}

[1] N. Joffin, B. Caillier, A. Garcia, P. Guillot, J. Galy, A. Fernandes, R. Mauricot, Opt. Mater. 28 (2006) 597-601.

[2] M. Kaczkan, D.A. Pawlak, S. Turczyński, M. Malinowski, Phys. Procedia 2 (2009) 391-406.

[3] L.-Y. Zhou, J.-S. Wei, J.-X. Shi, M.-L.Gong, H.-B. Liang, J. Lumin. 128 (2008) 1262-1266.

[4] S.A.M. Lima, M.R. Davolos, C. Legnani, W.G. Qiurino, M. Cremona, J. Alloys Compd. 418 (2006) 35-38.

[5] L. Zhang, B. Li, S. Yue, M. Li, Z. Hong, W. Li, J. Lumin. 128 (2008) 620-624.

[6] A. Bayrashev, W.P. Robbins, B. Ziaie, S. Actuators A 114 (2004) 244-249.

[7] Ph. Lanaerts, C. Görller-Walrand, K. Binnemans, J. Lumin. 117 (2006) 163-169.

[8] M. Villanueva-Ibanez, C. Le Luyer, C. Dujardin, L. Mugnier, Mater. Sci. Eng. B 105 (2003) 12-15.
[9] M.A. Fotopoulou, P.C. Ioannou, Anal. Chim. Acta 462 (2002) 179-185.

[10] Y. Wang, L. Feng, C. Jiang, Spectrochim. Acta, Part A 61 (2005) 2909-2914.

[11] H. Chakraborty, S. Mondal, M. Sarkar, Biophys. Chem. 137 (2008) 28-34.

[12] W. Qin, W. Lu, M. Tan, Anal. Chem. Acta 468 (2002) 287-292.

[13] S.B. Meshkova, A.V. Kiriyak, M.P. Tsvirko, V.P. Gogorognyuk, J. Anal. Chem. 63 (2008) 840-843.

[14] S. Hirata, T. Kajiya, M. Aihara, K. Honda, O. Shikino Talanta 58 (2002) 1185-1194.

[15] T. Pasinli, A.E. Eroğlu, T. Shahwan, Anal. Chim. Acta 547 (2005) 42-49.

[16] Q. Jia, X. Kong, W. Zhou, L. Bi, Microchem. J. 89 (2008) 82-87.

[17] B.M. Vanderborght, R.E. Van Grieken, Anal. Chem. 49 (1977) 311-316.

[18] J.S. Shih, L.M. Tsat, S.C. Wu, Analyst 110 (1985) 1387-1390.

[19] Y.S. Lin, Sep. Purif. Technol. 25 (2001) 39-55.

[20] M.A. Stylianou, V.J. Inglezakis, K.G. Moustakas, M.D. Loizidou, Desalination 224 (2008) 240-249.

[21] Sh. Wang, Chem. Eng. J. 156 (2010) 11-24.

[22] S. Coruh, Desalination 225 (2008) 41-57.

[23] S. Coruh, K. Gedik, I. Imamoglu, J. Hazard. Mater. 155 (2008) 385-392.

[24] N. Lihareva, L. Dimova, O. Petrov, Y. Tzvetanova, Micropor. Mesopor. Mater. 130 (2010) 32-37.

[25] V.O. Vasylechko, G.V. Gryshchouk, Yu.B. Kuz'ma, Book Abs., VIII Ukrainian-Polish Symposium on Theoretical and Experimental Studies of Interfacial Phenomena and their Technological Applications, Odesa, Ukraine, September 19-24, 2004, pp. 369-372.

[26] V.O. Vasylechko, G.V. Gryshchouk, Ya.M. Kalychak, A.S. Voloshinovskii, Ukraine Patent No. 52571, Bull. No. 16, 2010.

[27] V. Vasylechko, O. Vyviurska, G. Gryshchouk, Ya. Kalychak, Visn. Lviv Univ. Ser. Khim. 51 (2010) 151-160.

[28] V.O. Vasylechko, G.V. Gryshchouk, L.O. Lebedynets, Yu.B. Kuz'ma, L.O. Vasylechko, V.P. Zakordonskiy, Adsorp. Sci. Technol. 17 (1999) 125-134.

[29] Yu.I. Tarasevich, V.E. Polyakov, V.Zh. Penchev, G.N. Kirov, Kh.I. Minchev, I.G. Polyakov, [1] L.I. Badekha, Khim. Tekhnol. Vody 13 (1991) 132-140.

[30] Yu.I. Tarasevich, I.G. Polyakova, V.E. Polyakov, Colloid J. 65 (2003) 493-499.

[31] V.O. Vasylechko, L.O. Lebedynets, G.V. Gryshchouk, Yu.B. Kuz'ma, L.O. Vasylechko, T.M. Bernats'ka, L.O. Lebedynets, M.B. Kalytovs'ka, Adsorp. Sci. Technol. 14 (1996) 267-277. 
O. Vyviurska et al., Use of Na-modified clinoptilolite for the removal of terbium ions from aqueous solution

[32] M. Majdan, A. Gładysz-Płaska, S. Pikus, D. Sternik, O. Maryuk, P. Sadowski, J. Mol. Struct. 702 (2004) 95-102.

[33] G. Cao, M.J. Shah, W.A. Wachter, Zeolites and Mesoporous Materials at the Dawn of the $21^{\text {st }}$ Century, Studies in Surface Science and Catalysis, Part C, Elsevier, Amsterdam, 2001. Vol. 135. (CD Version).

[34] M. Trgo, J. Perić, J. Colloid Interface Sci. 260 (2003) 166-175.

[35] V.O. Vasylechko, G.V. Gryshchouk, Yu.B. Kuz'ma, V.P. Zakordonskiy, L.O. Vasylechko,
L.O. Lebedynets, M.B. Kalytovs'ka, Micropor. Mesopor. Mater. 60 (2003) 183-196.

[36] T. Wüst, J. Stolz, T. Armbruster, Am. Mineral. 84 (1999) 1126-1134.

[37] A. Godelitsas, T. Armbruster, Micropor. Mesopor. Mater. 61 (2003) 3-24.

[38] P. Misaelides, A. Godelitsas, S. Harissopoulos, I. Anonsis, J. Radioanal. Nucl. Chem. 247 (2001) 325-328.

[39] K. Gedic, I. Imamoglu, J. Hazard. Mater. 155 (2008) 385-392. 